\begin{tabular}{|c|c|c|c|c|}
\hline \multicolumn{5}{|c|}{ Proportions and OR for ADs among SBI recipients in comparison to SBI-free women } \\
\hline & $\begin{array}{l}\text { SBI free women } \\
n=98,604 n(\%)\end{array}$ & $\begin{array}{c}\text { SBI recipients } \\
n=24,651 \mathrm{n}(\%)\end{array}$ & $\begin{array}{c}\text { Unadjusted } \\
\text { OR } \\
(95 \% \mathrm{Cl})\end{array}$ & $\begin{array}{c}\text { Adjusted } \\
\text { OR }^{\star} \\
(95 \% \mathrm{Cl})\end{array}$ \\
\hline $\begin{array}{l}\text { Any auto-immune } \\
\text { disease }\end{array}$ & $22634(22.95)$ & $6510(26.41)$ & $\begin{array}{c}1.20(1.17- \\
1.24)\end{array}$ & $\begin{array}{c}1.21(1.17- \\
1.25)\end{array}$ \\
\hline Ankylosing spondylitis & $155(0.16)$ & $41(0.17)$ & $\begin{array}{c}1.06(0.75- \\
1.49)\end{array}$ & $\begin{array}{c}1.24(0.85- \\
1.80)\end{array}$ \\
\hline $\begin{array}{l}\text { Fibromyalgia/Chornic } \\
\text { fatigue syndrome }\end{array}$ & $6106(6.19)$ & $1997(8.10)$ & $\begin{array}{c}1.34(1.27- \\
1.41)\end{array}$ & $\begin{array}{c}1.33(1.25- \\
1.40)\end{array}$ \\
\hline Hyperthyroidism & $2945(2.99)$ & $870(3.53)$ & $\begin{array}{c}1.19(1.10- \\
1.28)\end{array}$ & $\begin{array}{c}1.17(1.07- \\
1.27)\end{array}$ \\
\hline Hypothyroidism & $10870(11.02)$ & $2979(12.08)$ & $\begin{array}{c}1.11(1.06- \\
1.16)\end{array}$ & $\begin{array}{c}1.11(1.05- \\
1.16)\end{array}$ \\
\hline Multiple sclerosis & $303(0.31)$ & $93(0.38)$ & $\begin{array}{c}1.23(0.97- \\
1.55)\end{array}$ & $\begin{array}{c}1.43(1.12- \\
1.82)\end{array}$ \\
\hline Psoriasis & $4594(4.66)$ & $1293(5.25)$ & $\begin{array}{c}1.13(1.06- \\
1.21)\end{array}$ & $\begin{array}{c}1.13(1.05- \\
1.21)\end{array}$ \\
\hline Psoriatic arthritis & $201(0.20)$ & $54(0.22)$ & $\begin{array}{c}1.07(0.80- \\
1.45)\end{array}$ & $\begin{array}{c}1.17(0.85- \\
1.61)\end{array}$ \\
\hline Rheumatoid arthritis & $970(0.98)$ & $278(1.13)$ & $\begin{array}{c}1.15(1.00- \\
1.31)\end{array}$ & $\begin{array}{c}1.17(1.01- \\
1.36)\end{array}$ \\
\hline Sarcoidosis & $187(0.19)$ & $93(0.38)$ & $\begin{array}{c}1.99(1.55- \\
2.56)\end{array}$ & $\begin{array}{c}1.95(1.49 \\
2.57)\end{array}$ \\
\hline Sjogren's syndrome & $344(0.35)$ & $123(0.50)$ & $\begin{array}{c}1.43(1.17- \\
1.76)\end{array}$ & $\begin{array}{c}1.55(1.24- \\
1.94)\end{array}$ \\
\hline $\begin{array}{l}\text { Systemic lupus } \\
\text { erythematosus }\end{array}$ & $457(0.46)$ & $117(0.47)$ & $\begin{array}{c}1.02(0.84- \\
1.26)\end{array}$ & $\begin{array}{c}1.03(0.83- \\
1.28)\end{array}$ \\
\hline $\begin{array}{l}\text { Systemic sclerosis } \\
\text { (Scleroderma) }\end{array}$ & $242(0.25)$ & $101(0.41)$ & $\begin{array}{c}1.67(1.33- \\
2.11)\end{array}$ & $\begin{array}{c}1.63(1.26- \\
2.11)\end{array}$ \\
\hline Vasculitis & $115(0.12)$ & $32(0.13)$ & $\begin{array}{c}0.90(0.61- \\
1.33)\end{array}$ & $\begin{array}{c}1.23(0.80- \\
1.89)\end{array}$ \\
\hline
\end{tabular}

${ }^{*}$ Adjusted for: age/socio-economic status/birth country/smoking status/breast cancer.

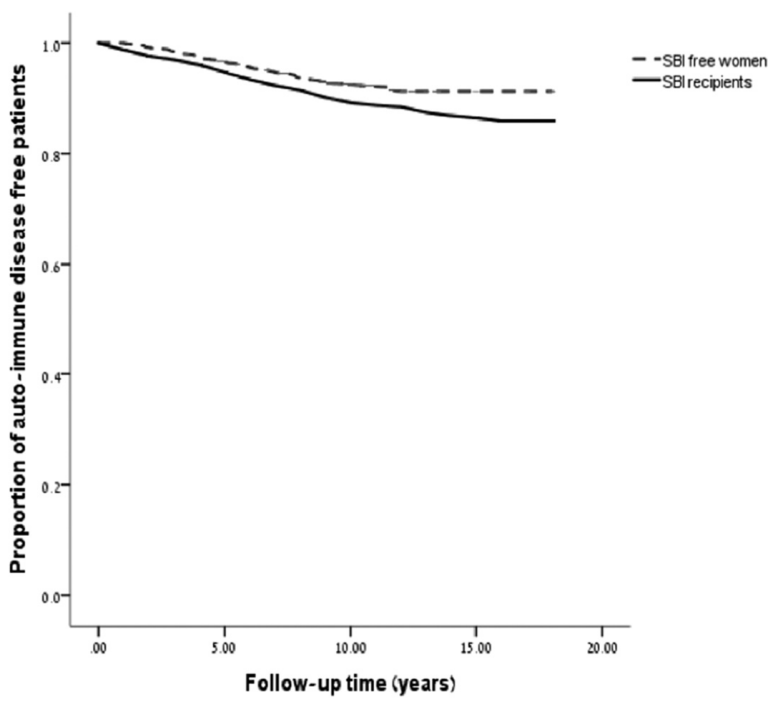

$P$-value from log rank test $<0.001$

Note: $S B=$ silicone breast implants

Abstract SAT0687 - Figure 1. Kaplan-Meier plot for diagnosis with an auto-immune among $\mathrm{SBI}$ recipients and SBI-free women $(\mathrm{n}=8906)$. $P$-value from log rank test $<0.001$. Note: $\mathrm{SB}=$ silicone breast implants

Conclusions: SBls seems to be associated with higher likelihood of autoimmune disease diagnosis.

Acknowledgements: None
Disclosure of Interest: None declared

DOI: 10.1136/annrheumdis-2018-eular.3886

\section{SAT0688 PROGRESSIVE DRIFT OF PATIENT POPULATIONS IN RHEUMATOID ARTHRITISCLINICAL TRIALS OVER TIME}

A. Kerschbaumer ${ }^{1}$, B. Bierbaumer ${ }^{2}$, J.S. Smolen ${ }^{1}$, D. Aletaha ${ }^{1}{ }^{1}$ Department of Medicine III (Chairman: Prof. Josef Smolen, MD), Medical University of Vienna, Vienna, Austria; ${ }^{2}$ Independent, Munich, Germany

Background: Rheumatoid arthritis (RA) is among the most intensively studied chronic inflammatory musculoskeletal diseases. Over the past two decades numerous new compounds have been tested in RA. Although the results from any new clinical trial in RA is usually interpreted in the context of existing data from previous trials, it is not clear whether trial populations are necessarily historically comparable.

Objectives: To understand secular trends and drifts in characteristics of patient populations enrolled in RA clinical trials.

Methods: We performed a systematic literature review of randomised, controlled double-blind trials, investigating biological therapies in RA. Reports were identified using PUBMED, EMBASE and the Cochrane Library. Populations were stratified into conventional disease modifying anti-rheumatic drug (cDMARD) naïve, cDMARD inadequate responders (IR), and biological DMARD IR. The following variables at baseline were extracted from reports: swollen and tender joint counts (SJC, TJC), pain, patient and evaluator global (PGA, EGA), acute phase measures (erythrocyte sedimentation rate, ESR and C-reactive protein, CRP), as well as the Health Assessment Questionnaire Disability Index (HAQ). In addition, we obtained the year of publication and the inclusion criteria of each trial. We then performed a mixed model meta-regression of year of publication on each of the mentioned baseline variables

Results: Out of 697 abstracts selected for screening, 73 studies were chosen as relevant; 3 studies with mixed populations were excluded, resulting in 70 studies included for analysis. Table 1 shows the observed medians and quartiles for the baseline characteristics. Meta-regression showed a significant decrease of SJC $(\beta=-0.415 ; p \leq 0.001)$, TJC $(\beta=-0.378 ; p \leq 0.001)$, and CRP $(\beta=-0.123 ; p \leq 0.001)$ over the years (figure 1); for all other core set measures, there was no trend or significance. Inclusion criteria showed similar trends over time for SJC $(\beta=-0.154$, $p \leq 0.001)$, TJC $(\beta=-0.243, p \leq 0.001)$, and CRP $(\beta=-0.065, p \leq 0.001)$.

\begin{tabular}{|c|c|c|c|}
\hline & DMARD NAIVE & csDMARD IR & bDMARD IR \\
\hline No of trials $(n)$ & 13 & 48 & 9 \\
\hline No of study arms (n) & 39 & 180 & 25 \\
\hline No of patients $(n)$ & 8894 & 23752 & 4584 \\
\hline Year of publication (YYYY) & $\begin{array}{c}2014(2009- \\
2016)\end{array}$ & $\begin{array}{l}2008(2003- \\
2012)\end{array}$ & $\begin{array}{c}2013(2008- \\
2016)\end{array}$ \\
\hline CRP (mg/dL) & $\begin{array}{l}2.59(2.27- \\
3.26)\end{array}$ & $2.08(1.67-3)$ & $2.1(1.08-3.11)$ \\
\hline $\operatorname{ESR}(\mathrm{mm} / \mathrm{h})$ & $49.4(42-52.8)$ & $\begin{array}{c}45.95(40.2- \\
49.9)\end{array}$ & $\begin{array}{c}46.85(39.2- \\
48.2)\end{array}$ \\
\hline Swollen Joints (0-66) & $16.65(16-20.3)$ & $\begin{array}{l}17.95(15.59- \\
20.4)\end{array}$ & $17.1(16.2-19)$ \\
\hline Tender Joints (0-68) & $28.05(25.5-31)$ & $\begin{array}{l}28.1(25.88- \\
31.7)\end{array}$ & $\begin{array}{c}28.75(25.6- \\
31.2)\end{array}$ \\
\hline Patient global assessment $(0-100)$ & $63.9(61.8-66)$ & $61(58-65)$ & $66.5(63-69.7)$ \\
\hline $\begin{array}{l}\text { Evaluator global assessment (0- } \\
\text { 100) }\end{array}$ & $63.6(62-65.6)$ & $62.05(59.7-65)$ & $66.45^{62-67}$ \\
\hline Patients pain assessment $(0-100)$ & $\begin{array}{l}62.5(60.9- \\
64.6)\end{array}$ & $\begin{array}{c}60.29(56.66- \\
65)\end{array}$ & $65(62-69)$ \\
\hline $\begin{array}{l}\text { Health assessment questionnaire } \\
(0-3)\end{array}$ & $1.54(1.5-1.63)$ & $1.51(1.41-1.66)$ & $1.7(1.6-1.74)$ \\
\hline
\end{tabular}




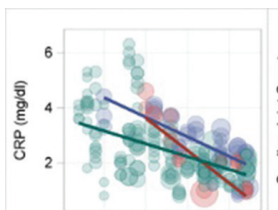

2000200520102015

Year

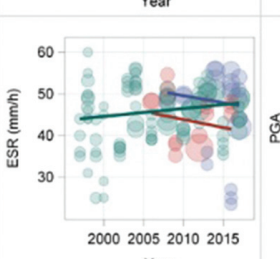

Year

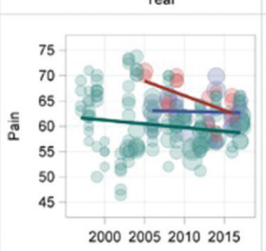

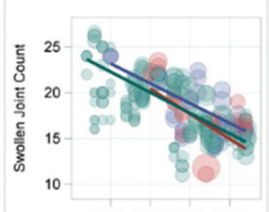
Year

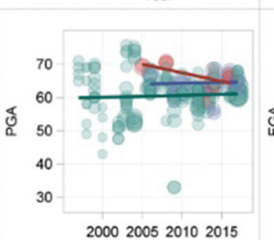

Year

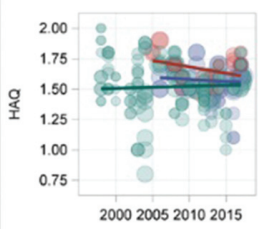

Yea 2000200520102015

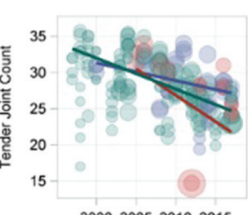

Year

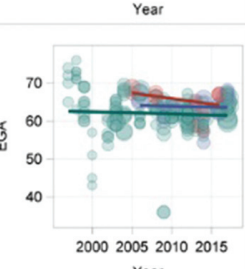

Year

\section{DMARD naive} bDMARD IR CSDMARD IR

Size of bubbles represent

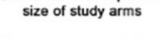

Lines represent weighted
linear regression lines

Conclusions: There is a progressive drift towards lower number of swollen and tender joints and lower CRP-levels at trial entry of time, which is at least partly related to a similar trend in inclusion criteria for RA. The constancy of patientreported outcomes suggests that the baseline activity is still perceived as similarly high. Differences in overall baseline inflammatory activity may pose a challenge for comparing newer with older trial results.

Disclosure of Interest: None declared

DOI: 10.1136/annrheumdis-2018-eular.6657

\section{SAT0689 THYMECTOMY IN PATIENTS WITH MYASTHENIA GRAVIS AND THE RISK OF AUTOIMMUNE RHEUMATIC DISEASES: A NATIONWIDE COHORT STUDY}

C.C. Chang ${ }^{1,2}$, J.-H. Chen ${ }^{3} .{ }^{1}$ Division of Allergy, Immunology and Rheumatology, Department of Internal Medicine, School of Medicine, College of Medicine, Taipei Mediacal University; ${ }^{2}$ Division of Rheumatology, Immunology and Allergy, Department of Internal Medicine, Taipei Medcial Universuty Hospital; ${ }^{3}$ Biostatistics Center and Graduate Institute of Data Science, College of Management, Taipei Medical University, Taipei, Taiwan, Province of China

Background: Previous studies have shown myasthenia gravis (MG) and autoimmune rheumatic diseases (ARDs) share common pathogenetic mechanisms. Objectives: Therefore, the present study investigated the possible relationship between MG and ARDs.

Methods: We analysed Taiwanese medical data from the Registry of Catastrophic Illness and identified patients with MG. From the entire general population data of the National Health Insurance Research Database, we randomly selected a comparison cohort that was frequency-matched by age (in 5 year increments), sex, and index date. We analysed the risk of ARDs by using a Cox proportional hazards regression model stratified by sex, age, and treatment.

Results: We enrolled 6478 patients with MG (58.03\% women; mean age, 50.55 years) and 25912 age- and sex-matched controls in the present study. The risk of total ARDs was 6.25 times higher in the MG cohort than in the non-MG cohort after adjustment for age and sex. Furthermore, the MG cohort was associated with a significantly higher risk of primary SS (pSS), SLE, and other ARD types (adjusted hazard ratios [HRs]: 15.84 [95\% Cl: 8.39-23.91]; 11.32 [95\% Cl: 5.04-25.429]; and 4.07 [95\% Cl: $1.31-12.62]$, respectively). MG cohort who received thymectomy had an increased risk of RA, pSS, and SLE (adjusted HRs: 4.41; 15.06; and 23.68, respectively).
Conclusions: The present nationwide cohort study revealed an association between MG and incident ARDs. MG cohort who received thymectomy had an increased risk of RA, pSS, and SLE. Future studies are needed to elucidate the underlying pathogenesis and to translate them into clinical therapeutic options.

\section{REFERENCES:}

[1] Voight BF, Cotsapas C. Human genetics offers an emerging picture of common pathways and mechanisms in autoimmunity.Curr Opin Immunol 2012;24:552-557.

[2] Parkes M, Cortes A, van Heel DA, Brown MA. Genetic insights into common pathways and complex relationships among immune-mediated diseases. Nat Rev Genet 2013;14:661-673

[3] Fang F, Sveinsson O, Thormar G, et al. The autoimmune spectrum of myasthenia gravis: a Swedish population-based study. J Intern Med 2015;277(5):594-604.

[4] Christensen PB, Jensen TS, Tsiropoulos I, et al. Autoimmune diseases in myasthenia gravis. A population-based study Acta Neurol Scand 1995;91 (3):192-195.

Disclosure of Interest: None declared

DOI: 10.1136/annrheumdis-2018-eular.4375

\section{SAT0690 THE ASSOCIATION BETWEEN SARCOIDOSIS AND ISCHAEMIC HEART DISEASE - A BIG DATA ANALYSIS}

D. Katz ${ }^{1,2}$, S. Tiosano ${ }^{3,4}$, D. Comaneshter ${ }^{5}$, A.D. Cohen ${ }^{5,6}$, H. Amital ${ }^{7,8}$.

${ }^{1}$ Zabludowicz Center for Autoimmune Diseases, Sheba Medical Center, Tel Hashomer, Ramat Gan; ${ }^{2}$ Faculty of Medicine, Hebrew University of Jerusalem, Jerusalem; ${ }^{3}$ Department of Medicine 'B' and Zabludowicz Center for Autoimmune Diseases, Sheba Medical Center, Tel-Hashomer, Ramat Gan; ${ }^{4}$ Sackler Faculty of Medicine, Tel-Aviv University; ${ }^{5}$ Chief Physician's Office, Clalit Health Services, Tel Aviv, ${ }^{6}$ Siaal Research Center for Family Medicine and Primary Care, Faculty of Health Sciences, Ben Gurion University of the Negev, Beer Sheva; ${ }^{7}$ Department of Medicine ' $B$ ' and Zabludowicz Center for Autoimmune Diseases, Sheba Medical Center, Tel-Hashomer, Ramat Gan; ${ }^{8}$ Sackler Faculty of Medicine, Tel-Aviv University, Tel Aviv, Israel

Background: Sarcoidosis is an inflammatory disease characterised by the hallmark sign of non-caseating granulomas ${ }^{1,2}$. In the past decade a consensus has formed regarding the pivotal role of inflammation in atherosclerosis ${ }^{3}$. Since this discovery the association between chronic inflammatory states and ischaemic heart disease was confirmed in several rheumatic diseases ${ }^{4}$. Therefore, the constant state of inflammation to which sarcoidosis patients are exposed might pose as a risk factor for ischaemic heart disease.

Objectives: The aim of this study is to assess the relation between sarcoidosis and Ischaemic heart disease and its prognostic significance.

Methods: Based on data from Clalit Health Services (CHS), Israel's largest health maintenance organisation, the medical records of 3993 sarcoidosis patients and 19856 controls were acquired. Controls were matched to sarcoidosis patients according to age and sex. Chi-square and student t-tests were used in order to compare variables distribution in the cohort. Variables associated with ischaemic heart disease were assessed by logistic regression model. Log-rank test was performed for survival analysis, while Cox proportional hazards method was utilised to evaluate variables related to increased risk of all-cause mortality.

Results: Matched by sex and age - both sarcoidosis group and the control group were composed from $63 \%$ females with mean age being 56 years. Compared to the control group, sarcoidosis patients had a higher proportion of ischaemic heart disease, presenting with $856(21.4 \%)$ cases whereas the control group had only 2999 cases $(15.1 \%, p<0.001)$. The association between sarcoidosis and ischae mic heart disease was demonstrated by a multivariate analysis, (adjusted OR $1.503,95 \% \mathrm{Cl} 1.361-1.660)$. A 15 year follow up revealed increased mortality among sarcoidosis patients - as $710(17.8 \%)$ of sarcoidosis patients had passed away while $2121(10.7 \%)$ deaths were reported in the control group $(p<0.001)$. In a multivariate model, sarcoidosis patients were found to be in increased risk for all-cause mortality compared to the control group (adjusted HR $1.95,95 \% \mathrm{Cl}$ 1.75-2.14). 


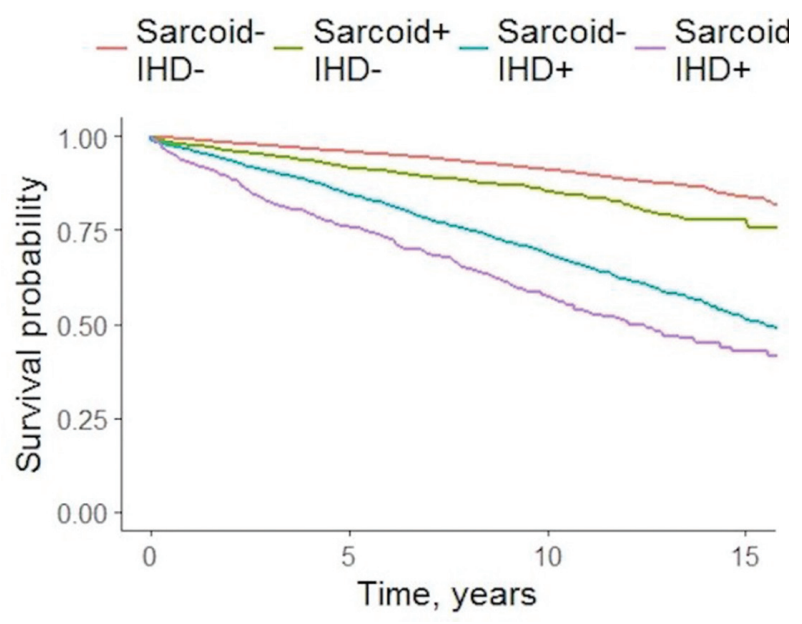

Conclusions: Sarcoidosis is associated with an increased risk for ischaemic heart disease and all-cause mortality. Patients with co-morbidity of sarcoidosis and ischaemic heart disease should be treated accordingly.

\section{REFERENCES:}

[1] Markevitz, N, Epstein Shochet G, Levi Y, Israeli-Shani L, Shitrit D. Sarcoidosis in Israel: Clinical Outcome Status, Organ Involvement, and LongTerm Follow-Up. Lung 2017;195;419-424.

[2] Valeyre D, et al. Sarcoidosis. Lancet (London, England) 2014;383;115567.

[3] Willerson JT, Ridker PM. Inflammation as a cardiovascular risk factor. Circulation 2004;109:II2-10.

[4] Shoenfeld Y, et al. Accelerated Atherosclerosis in Autoimmune Rheumatic Diseases. Circulation 2005;112:3337-3347.

Disclosure of Interest: None declared

DOI: 10.1136/annrheumdis-2018-eular.6887

\begin{tabular}{|l|l}
\hline SAT0691 & ADHERENCE TO DISEASE-MODIFYING DRUGS IN \\
& CHRONIC INFLAMMATORY RHEUMATIC DISEASES: \\
& SEVERAL QUESTIONNAIRES, DIVERSE PATIENT \\
& CHARACTERISTICS AND SOME EFFICACIOUS \\
& INTERVENTIONS - A SYSTEMATIC LITERATURE \\
& REVIEW
\end{tabular}

D. Puyraimond-Zemmour, X. Romand, M. Lavielle, A. Molto, P. Gaudin, M. Soubrier, C. Beauvais, D. Wendling, E. Senbel, S. Pouplin, R.-M. Flipo, C. Richez, A. Saraux, L. Gutermann, M. Mézière, M. Dougados, L. Gossec. Rencontres d'Experts 2017 Working Group, Paris, France

Background: In chronic inflammatory rheumatic diseases (CIRDs), adherence to disease-modifying drugs (DMD) is only moderate. Non-adherence may lead to complications, unnecessary treatment switches and heightened costs. Physicians are often at a loss when faced with non-adherence.

Objectives: To obtain an overview of how to measure adherence, who to screen particularly (risk factors of non adherence) and interventions to enhance medication adherence to $\mathrm{DMD}$ in patients with CIRDs.

Methods: A systematic literature review was performed in Pubmed, Cochrane, Embase and websites in 2017. All english and french studies related to methods to measure non-adherence, risk factors regrouped in 5 domains according to World Health Organisation (patient characteristics, health status, treatments, socio-economic conditions and relations with caregivers and the health system) and interventions for non-adherence regrouped in 5 modalities (educational, behavioural, cognitive behavioural, multicomponent interventions or others) were selected. The scope was limited to CIRDs (i.e., rheumatoid arthritis (RA), spondyloarthritis $(\mathrm{SpA})$, psoriatic arthritis ( $\mathrm{Ps} A)$, cristal-induced arthritis (CIA), connective tissue diseases (CTD), vasculitis and auto-inflammatory diseases), and to DMD (i.e., mainly conventional DMARDs, biologics and targeted synthetic DMARDs).
Results: After screening 1131 publications and 194 other documents, 231 relevant papers were analysed for measuring adherence $60 \%$ in $\mathrm{RA}, 8 \%$ in $\mathrm{SpA}, 6 \%$ in PsA, $11 \%$ in CIA and $15 \%$ in CTD), 117 for predicting non-adherence (55\% in RA, $9 \%$ in SpA, 14\% in gout and $22 \%$ in CTD) and 22 for improving adherence (72\% in RA, $8 \%$ in SpA, $16 \%$ in systemic lupus and $4 \%$ in gout). Objective measurements of non-adherence included: delivery data (total number of use: $n=92$ ), pill counts $(n=8)$, medication event monitoring system $(n=9)$, blood level assessments $(n=7)$. Subjective measurements included: patient global assessment $(n=57)$, and 4 questionnaires. The most used questionnaire was the Morisky Medication Adherence Scale and the most widely validated in rheumatology were the Compliance Questionnaire on Rheumatology and the Medication Adherence Self-report Inventory. Around 100 predictive factors were identified. Polymedication, mood disorders, lack of information and poor physician-patient relationship were associated with lower adherence. Regarding management options for nonadherence, 13/22 studies were randomised controlled trials (1535 patients) and only $5(38 \%)$ were positive (774 patients). Educational interventions were the most represented with the highest level of evidence: 8/13 trials (1017 patients) with $4 / 8$ yielding positive results.

Conclusions: Despite the importance of medication adherence in CIRDs, this review revealed limitations in methods to measure non-adherence, a multiplicity of non-adherence risk factors and a relative lack of evidence on interventions to improve medication adherence. It's important to improve the assessment and optimisation of adherence in CIRDs.

Acknowledgements: AbbVie France funded this initiative but played no role in the points to consider.

Disclosure of Interest: None declared

DOI: 10.1136/annrheumdis-2018-eular.3943

\section{SAT0692 1 BREASTFEEDING IS NOT ASSOCIATED WITH ANTI- CITRULLINATED ANTIBODIES DEVELOPMENT IN INDIVIDUALS AT RISK FOR RHEUMATOID ARTHRITIS}

D. Alpizar-Rodriguez ${ }^{1}$, M. Ruediger ${ }^{2}$, B. Möller ${ }^{3}$, J. Dudler ${ }^{4}$, A. Ciurea ${ }^{5}$, P. Zufferey ${ }^{6}$, D. Kyburz ${ }^{7}$, U. Walker ${ }^{7}$, I. von Mühlenen ${ }^{7}$, P. Roux-Lombard ${ }^{1}$, C. Lamacchia', C. Gabay ${ }^{1}$, A. Finckh ${ }^{1} .{ }^{1} H U G$, Geneva: ${ }^{2}$ KSSG, St Gallen; ${ }^{3}$ Inselspital, Bern; ${ }^{4}$ HFR, Fribourg; ${ }^{5}$ USZ, Zurich; ${ }^{6} \mathrm{CHUV}$, Lausanne; ${ }^{7}$ USB, Basel, Switzerland

Background: 'Systemic autoimmunity associated with rheumatoid arthritis' (RA), is a pre-clinical stage preceding the onset of clinical RA, characterised by the presence of autoantibodies, such as anti-citrullinated protein antibodies (ACPA) or anti-carbamylated protein antibodies (antiCarP). Breastfeeding has been proposed as a protective factor for RA development, ${ }^{1}$ but there are some controversies. ${ }^{2}$ To establish the causal role of a putative risk factor, longitudinal studies are needed, in particular in the pre-stages of RA development.

Objectives: To study the association between breastfeeding and the development of systemic autoimmunity associated with RA.

Methods: This ongoing prospective study includes individuals genetically at risk of developing RA, namely first-degree relatives of RA patients (RA-FDR). Individuals without clinical evidence of RA were enrolled, and assessed yearly clinically and biologically. We included all RA-FDR women with available ACPA status (anti-CCP 2, 3.1 or 3.0) and information about breastfeeding. The primary outcome was ACPA positivity. The exposure of interest was breastfeeding and duration of breastfeeding (categorised as $0,1-7$ and $\geq 7$ months). The presence of antiCarP was a secondary outcome. We used logistic regression to analyse univariable and multivariable associations.

Results: A total of 882 women were included, of which $57(6 \%)$ were ACPA positive. The characteristics of ACPA positive and negative participants were balanced, except for an older age in ACPA positives (median 52 versus 45 years table 1). In the univariable analysis, ACPA positivity was not significantly associated with breastfeeding (OR 1.5, $\mathrm{p}=0.16$ ) or with breastfeeding duration $(\mathrm{OR}=1.8$, $\mathrm{p}=0.14$ ). In the multivariable analysis adjusted by age, smoking, number of pregnancies and years of education, there was a weak, but not significant, association between breastfeeding for more than 7 months and ACPA positivity (OR 2.16 $\mathrm{p}=0.10)$. Among 728 women with available antiCarP results, $70(10 \%)$ were positive, of which $27(40 \%)$ breastfed. Breastfeeding for more than 7 months was not significantly associated with antiCarP in univariable or multivariable analyses (OR $1.3, p=0.52$ and OR $1.9, p=0.16$, respectively) 